\title{
Detecting transmission and reassortment events for influenza A viruses with genotype profile method
}

\author{
Changzheng Dong ${ }^{*}{ }^{*}$, Liya Ying ${ }^{\dagger}$ and Dongfang Yuan
}

\begin{abstract}
Evolutionary events of transmission and reassortment for influenza A viruses were traditionally detected by phylogenetic analysis for influenza viruses' eight gene segments. Because the phylogenetic analysis can be complex, we developed genotype profile method which packaged the phylogenetic algorithms to analyze combination patterns of gene segments and integrated epidemiology knowledge. With the method, the analysis of reassortment and transmission becomes a simple and reliable process that combines genotypes, which is identical for the biological process of the virus. An application called IVEE that implements the method is available for all academic users to apply the method http://snptransformer.sourceforge.net. Furthermore, we found that a previous summary of the reassortment events in swine influenza A viruses may be inaccurate.
\end{abstract}

Keywords: influenza A virus, genotype, genotype profile method, reassortment, transmission, phylogenetic analysis, gene segment, IVEE

\section{Background}

Influenza A viruses annually cause seasonal epidemics and occasional global pandemics in humans. Three pandemics occurred in the 20th century, in 1918, 1957 and 1968, which were the result of the transmission of avian viruses or a reassortment between human and avian viruses that greatly changed virus antigenicity $[1,2]$. At the end of 2008 or the beginning of 2009, a novel swine reassortant was transmitted to humans [3], and a global pandemic broke out in Mexico and USA in April 2009 [4]. Researchers confirmed that the reassorted virus consisted of six gene segments that emerged from triplereassortant viruses circulating in North American swine and two gene segments from Eurasian avian-like swine H1N1 viruses $[3,4]$. Because the common ancestor of the new swine-origin influenza A (H1N1) virus (S-OIV) and its most closely related swine viruses existed approximately 10 years ago, the reassortant viruses may have been circulating in pigs for several years before their transmission to humans [3]. Due to the lack of

\footnotetext{
* Correspondence: dongchangzheng@nbu.edu.cn

+ Contributed equally

School of Medicine, Ningbo University, Ningbo, 315211, China
}

swine surveillance, the details regarding the reassortment event are unclear.

Phylogenetic analysis has been an essential method for research into the molecular evolution of influenza A viruses, especially for cross-host transmission and reassortment). Holmes et al. sequenced 156 complete genomes of human H3N2 influenza A viruses collected between 1999 and 2004 from New York, USA, and phylogenetic analysis revealed that multiple reassortment events had occurred among the co-circulating clades [5]. Nelson et al. showed that segmental reassortment has played an important role in the genomic evolution of H1N1 since 1918 and that intra-subtype reassortment appeared to be an important process in the evolution and epidemiology of H1N1 influenza A virus [6]. Nelson et al. found that multiple clades of both $\mathrm{H} 1 \mathrm{~N} 1$ and H3N2 entered and co-circulated in the United States during the 2006-2007 influenza season, even in localities that were distant from major metropolitan areas [7]. These data were concordant with other research by the same group concluding that the stochastic processes of viral migration and clade reassortment played a vital role in shaping short-term evolutionary dynamics [8]. Vijaykrishna et al. discovered a novel swine reassortant 
in Hong Kong containing genes from both 2009 S-OIV and triple-reassortant virus which implied that swine might be a reservoir of reassortment for 2009 S-OIV [9]. Li et al. revealed avian reassortment patterns of highly pathogenic avian influenza (HPAI) H5N1 virus in eastern Asia [10] and the HAPI H5N1 virus had crosshost transmitted to human and caused fatal respiratory illness [11].

Traditionally, transmission and reassortment events have been mostly revealed by separate phylogenetic analysis for the eight gene segments [5-11]. This analysis method is not so straightforward, and the key process lies in identifying the lineages to which each gene segment belongs, a process that requires professional knowledge about numerous virus lineages. Rabadan et al. proposed an interesting method for revealing potential reassortment that calculates the paired nucleotide differences of the third codon positions between the same segments of any two virus strains $[12,13]$. If the two viruses have a common origin, the differences between all eight segment pairs should be proportional. In contrast, a violation of this rule probably indicates potential reassortment events. The method sounds reasonable; however, several factors may interfere with the calculation of the differences, such as time since divergence, number of generations and geographical isolation. Most importantly, it is difficult to parse the exact parents for potential reassortment. Lu et al. introduced the concept of genotype to define gene segment combinations [14] and developed an online tool called FluGenome [15] to determine genotypes for influenza A viruses and to detect virus reassortment in theory. Lineages for each segment are assigned by a cutoff of $10 \%$ nucleotide difference by $\mathrm{p}$-distance in the phylogenetic tree of all nearly complete sequences of influenza A viruses (see Figure 1). The genotypes can be determined by comparing the genomic sequences of new viruses with the genome database using the BLAST algorithm. The best BLAST results are used to assign lineages to the viruses and create genotypes by the sequential combination of the lineages for each segment in the gene order. Thus, the nomenclature of influenza A viruses consists of all eight gene segments, rather than the serotype of hemagglutinin and neuraminidase alone. Reassortment can be detected, in theory, by combining the known genotypes in the database. Unfortunately, FluGenome only provided the process for determining the genotypes, and the analysis process for the reassortment was not implemented directly. Furthermore, the hundreds of genotypes that are collected in the database complicate the analysis even in theory.

In this study, we introduce the concept of "genotype profile" based on "genotype" to describe classic or dominant virus strains. With genotype profiles, the genotypes for the viruses were divided into several basic genotypes and various rare genotypes that may be transmitting viruses or reassortants. Employing genotype profile method, analyzing reassortment and transmission events is a simple and reliable process that combines basic genotypes, similar to the biological process of the virus, while complex phylogenetic analysis is packaged under the method. An application called IVEE that implements the method is available for all academic users to apply the method.

\section{Methods}

\section{Genotypes}

"Genotype" was previously defined by Lu et al. as a sequential combination of the lineages for each of the eight segments in an influenza virus genome [14]. A letter was assigned to each lineage of PB2, PB1, PA, NP and $\mathrm{M}$, and a number followed by a letter was assigned to each lineage of HA, NA and NS, with the number representing the serological subtype or allele. For example, $[\mathrm{A}, \mathrm{D}, \mathrm{B}, 3 \mathrm{~A}, \mathrm{~A}, 2 \mathrm{~A}, \mathrm{~B}, 1 \mathrm{~A}]$ is the genotype of human seasonal influenza virus subtype H3N2 with $\mathrm{PB} 2$ $\left(1^{\text {st }}\right.$ position $)$ of lineage $A, P B 1$ ( $2^{\text {nd }}$ position) of lineage D, PA ( $3^{\text {rd }}$ position) of lineage B, HA ( $4^{\text {th }}$ position) subtype 3 of lineage A, NP ( $5^{\text {th }}$ position) of lineage A, NA ( $6^{\text {th }}$ position) subtype 2 of lineage A, MP ( $7^{\text {th }}$ position) of lineage $B$ and NS ( $8^{\text {th }}$ position) subtype 1 of lineage A, which follows the numbering system of influenza genome segments.

We downloaded the genotype information for all influenza A viruses of humans, swine and avian species in the database on $10^{\text {th }}$ Sep, 2010 from FluGenome [15]. In total, there were 3161, 324 and 2572 genomes for human, swine and avian viruses, respectively, and the number of types of corresponding genotypes was 26,40 and 397, respectively. Two virus strains (A/Texas/09/2009 and A/Canada-ON/ RV1527/2009) were used to determine the genotypes of 2009 S-OIV because 2009 S-OIVs and their genotypes were not included in the FluGenome database till now. We downloaded their complete genomic sequences from the NCBI Influenza Virus Resource [16] and determined their genotypes via FluGenome. Most of the lineages of gene segments could be confirmed directly; however, the lineage of NA was assigned using looser parameters $(80 \%$ coverage and $80 \%$ identity).

\section{Genotype profiles}

We defined genotype profiles as lists of all genotypes of classic or predominant virus strains for humans, swine or avian species to filter hundreds of not so important genotypes and import epidemiological knowledge for viruses (see Table 1). With such a definition, the genotypes for the viruses could be divided into common genotypes and rare genotypes. Common genotypes meant 


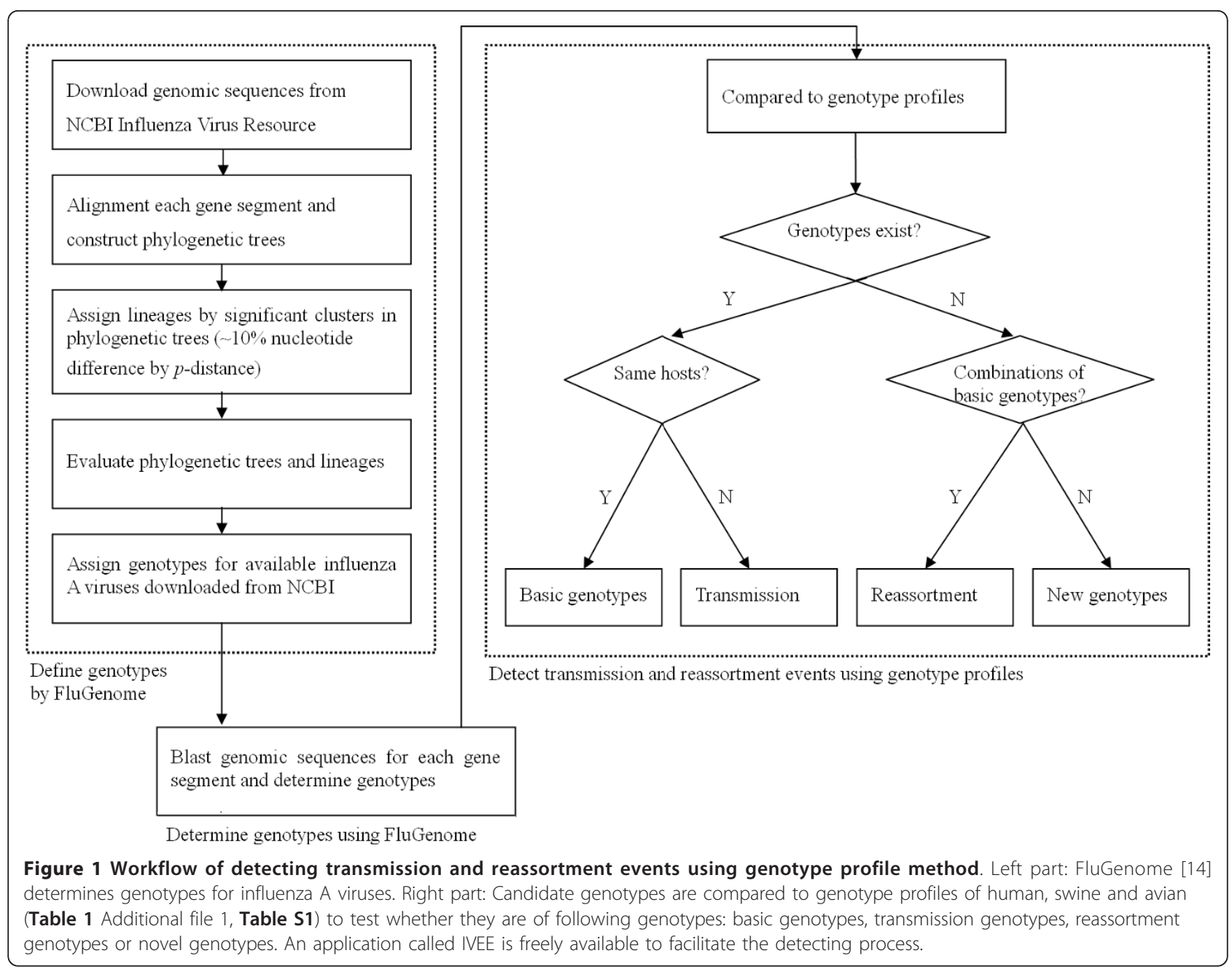

that these genotypes occur frequently and mainly refer to classic or predominant virus strains, whereas rare genotypes have low frequencies. However, in some cases, such as human infecting, highly pathogenic avian $\mathrm{H} 5 \mathrm{~N} 1$ viruses, they should not be considered genotypes in the human genotype profile (we name them basic genotypes) because they have not yet adapted to human hosts, despite the fact that these genotypes were observed in human hosts with high frequencies. Similarly, some reassortants that have not adapted to their hosts may be isolated with high frequency due to frequent sampling. Thus, the difference between common genotypes and basic genotypes depends on whether the hosts are natural hosts or new hosts after adaptation and are judged based on epidemiological knowledge of influenza A viruses. We further assumed that most of the viruses that have rare genotypes are transmitting viruses or reassortants that emerged from combinations of basic genotypes, and would test the hypothesis later. Occasionally some rare genotypes such as $[\mathrm{A}, \mathrm{A}, \mathrm{A}, 1 \mathrm{~A}$,
A, 1A, B, 1A] for A/Brevig Mission/1/1918 had low frequencies due only to the lack of sampling. These genotypes were all excluded from the genotype profiles to decrease the complexity of the genotype profiles. Genotype profiles for human, swine and avian species were established by the following steps: (i) divide genotypes for the viruses into common genotypes and rare genotypes with a cutoff of 5 for genotype frequencies; (ii) common genotypes were further checked based on knowledge of the evolutionary history of influenza A virus to distinguish basic and non-basic genotypes; (iii) basic genotypes in genotype profiles were further classified into groups and subtypes; (iv) rare genotypes and non-basic genotypes were analyzed following the process for detecting transmission and reassortment events described below.

\section{Detecting transmission and reassortment events}

After the genotypes of the candidate viruses are determined, the genotypes are compared to genotype profiles 
Table 1 Genotype profiles for human, swine and avian influenza A viruses

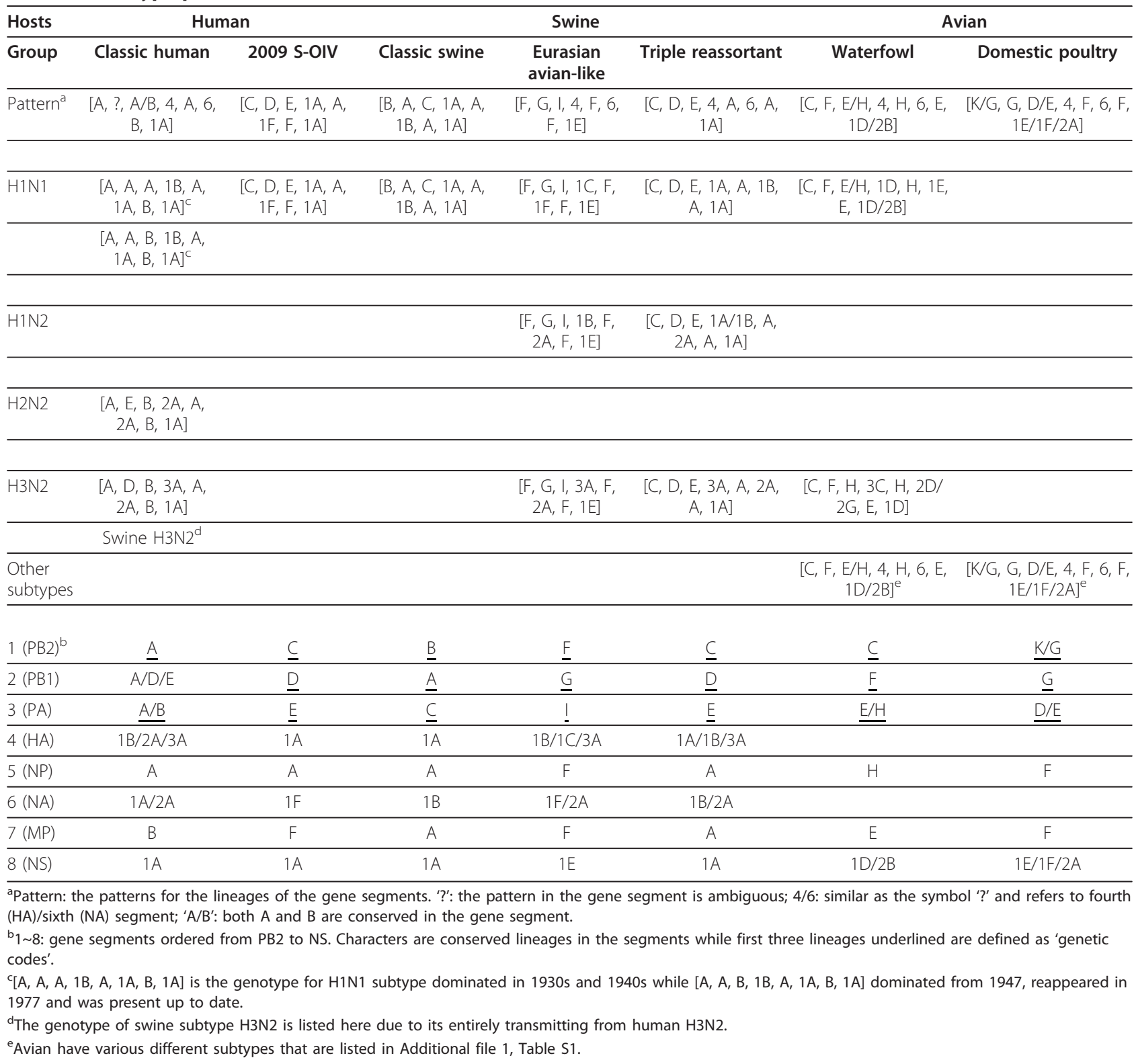

to detect transmission and reassortment events (see Figure 1). The detecting process includes two steps. First, ascertain whether the genotypes exist in the genotype profiles. If the genotypes of candidate viruses exist in the genotype profiles, the genotypes are basic genotypes as long as the sampling hosts are the same as the hosts of the basic genotype or transmission genotypes when they are different. Thus, the virus is a transmission virus if it has switched hosts from the natural host to the host from which it was sampled. For example, the frequent observation of avian genotypes [K, G, D, 5J, F, $1 \mathrm{~J}, \mathrm{~F}, 1 \mathrm{E}]$ and $[\mathrm{G}, \mathrm{G}, \mathrm{E}, 5 \mathrm{~J}, \mathrm{~F}, 1 \mathrm{G}, \mathrm{F}, 1 \mathrm{E}]$ in humans provided evidence that humans were infected with avian H5N1 viruses (see Table 2). Otherwise, the genotypes are considered potential reassortants only if they do not exist in the genotype profiles. Next, observe the characteristics of the lineages of the genotypes and infer the possible reassortment parents by combining the basic genotypes of the genotype profiles. In most cases, the reassortment parents and how they were combined can be easily concluded, except for some novel genotypes that have emerged from unknown origins. We can then test the hypothesis that most of the viruses that have rare genotypes are transmitting viruses or reassortants. 
Table 2 Transmission and reassortment events of human and swine influenza A viruses

\begin{tabular}{|c|c|c|c|c|c|c|c|c|}
\hline \multirow[t]{2}{*}{ Subtype } & \multicolumn{4}{|c|}{ Human } & \multicolumn{4}{|c|}{ Swine } \\
\hline & Genotype & Events $^{a}$ & N. ${ }^{b}$ & Year $^{c}$ & Genotype & Events & N. & Year \\
\hline \multirow[t]{13}{*}{$\mathrm{H} 1 \mathrm{~N} 1$} & $\begin{array}{l}{[A, A, A, 1 A, A, 1 A,} \\
B, 1 A]\end{array}$ & $\begin{array}{l}\text { First transmission } \\
\text { from avian?[17] }\end{array}$ & 1 & $1918(1)$ & {$[A, A, B, 1 B, A, 1 A, B, 1 A]$} & Transmission from human [42] & 4 & 2004-2006 \\
\hline & $\begin{array}{l}{[A, A, C, 1 B, A, 1 A,} \\
B, 1 A]\end{array}$ & Unknown $^{d}$ & 1 & 1936 & {$[A, A, C, 1 A, A, 1 A, A, 1 A]$} & Unknown $^{d}$ & 1 & $1931(4)$ \\
\hline & $\begin{array}{l}{[A, A, C, 1 A, A, 1 B,} \\
B, 1 A]\end{array}$ & $\begin{array}{l}\text { Transmission from } \\
\text { swine }^{d}[43]\end{array}$ & 1 & $1976(2)$ & {$[A, A, C, 1 A, A, 1 A, B, 1 A]$} & Unknown $^{d}$ & 1 & $1935(5)$ \\
\hline & $\begin{array}{l}{[A, D, B, 1 B, A, 1 A,} \\
B, 1 A]\end{array}$ & $\begin{array}{l}\text { Reassortant by } \mathrm{H} 3 \mathrm{~N} 2 \\
\text { \& H1N1 }\end{array}$ & 5 & 1978-1979 & {$[A, G, I, 1 C, F, 1 F, F, 1 E]$} & $\begin{array}{l}\text { Reassortant by EA \& human }{ }^{d} \\
\text { [44] }\end{array}$ & 1 & 1979 \\
\hline & $\begin{array}{l}{[B, A, C, 1 A, A, 1 B,} \\
A, 1 A]\end{array}$ & Transmission from CS & 4 & 1976-1991 & {$[B, D, C, 1 A, A, 1 B, A, 1 A]$} & Reassortant by TRIG \& CS [45] & 3 & 2004 \\
\hline & $\begin{array}{l}{[C, D, E, 1 A, A, 1 B} \\
A, 1 A]\end{array}$ & $\begin{array}{l}\text { Transmission from } \\
\text { TRIG [46] }\end{array}$ & 1 & 2005 & {$[C, A, C, 1 A, B, 1 A, B, 1 A]$} & Unknown $^{d}$ & 3 & 1931-1942 \\
\hline & $\begin{array}{l}{[C, D, E, 1 B, A, 1 A,} \\
A, 1 A]\end{array}$ & $\begin{array}{l}\text { Reassortant by TRIG \& } \\
\text { H1N1 [37] }\end{array}$ & 3 & 2009 & {$[C, D, C, 1 A, A, 1 B, A, 1 A]$} & Reassortant by TRIG \& CS [45] & 1 & 2003 \\
\hline & $\begin{array}{l}{[C, A, C, 1 A, B, 1 A} \\
B, 1 A]\end{array}$ & Unknown $^{d}$ & 2 & 1982-1987 & {$[C, D, E, 1 B, A, 1 A, A, 1 A]$} & TRIG \& human H1N1 [47] & 2 & 2005 \\
\hline & & & & & {$[C, D, E, 1 C, A, 1 F, F, 1 A]$} & TRIG \& EA [35] & 1 & 2010 \\
\hline & & & & & {$[C, F, E, 1 D, H, 1 E, E, 2 B]$} & Transmission from avian [48] & 1 & 2002 \\
\hline & & & & & {$[F, G, I, 1 A, F, 1 F, F, 1 E]$} & Reassortant by EA \& CS [49] & 1 & 2000 \\
\hline & & & & & {$[F, G, I, 1 A, A, 1 B, F, 1 E]$} & Reassortant by EA \& CS [3] & 2 & 2001 \\
\hline & & & & & {$[F, G, I, 1 C, F, 1 F, F, 1 A]$} & Reassortant by EA \& TRIG [9] & 10 & 2009 \\
\hline \multirow[t]{6}{*}{ H1N2 } & $\begin{array}{l}{[A, D, B, 1 B, A, 2 A} \\
B, 1 A]\end{array}$ & $\begin{array}{l}\text { Reassortant by H3N2 } \\
\text { \& H1N1 [50,51] }\end{array}$ & 26 & $2002-2003$ & {$[A, D, B, 1 B, A, 2 A, B, 1 A]$} & $\begin{array}{l}\text { Reassortant by H3N2 \& human } \\
\text { H1N1 [45] }\end{array}$ & 1 & 2003 \\
\hline & & & & & {$[B, A, C, 1 A, A, 2 A, A, 1 A]$} & $\begin{array}{l}\text { Reassortant by CS \& H3N2 } \\
{[49,52]}\end{array}$ & 4 & 1980-2004 \\
\hline & & & & & {$[B, D, C, 1 B, A, 2 A, A, 1 A]$} & Reassortant by TRIG \& CS [45] & 2 & 2004 \\
\hline & & & & & {$[C, D, E, 1 A, A, 2 A, F, 1 A]$} & Reassortant by TRIG \& EA [3] & 2 & 2003-2004 \\
\hline & & & & & {$[F, G, I, 1 A, A, 2 A, F, 1 E]$} & Reassortant by EA \& CS [3] & 1 & 2001 \\
\hline & & & & & {$[F, G, I, 1 A, F, 2 A, F, 1 A]$} & Reassortant by EA \& CS [9] & 1 & 2009 \\
\hline $\mathrm{H} 2 \mathrm{~N} 1$ & $\begin{array}{l}{[A, A, B, 2 B, A, 1 A} \\
B, 1 A]\end{array}$ & $\begin{array}{l}\text { Reassortant by H1N1 } \\
\text { \& H2N2? }\end{array}$ & 1 & 1977 & & & & \\
\hline H2N3 & & & & & {$[C, D, E, 2 H, A, 3 A, A, 1 A]$} & $\begin{array}{l}\text { Reassortant by TRIG \& avian } \\
\text { [53] H2N3 [53] }\end{array}$ & 2 & 2006 \\
\hline $\mathrm{H} 3 \mathrm{~N} 1$ & & & & & {$[C, D, E, 3 A, A, 1 B, A, 1 A]$} & $\begin{array}{l}\text { Reassortant by TRIG \& CS } \\
{[54,55]}\end{array}$ & 5 & 2004-2006 \\
\hline \multirow[t]{3}{*}{$\mathrm{H} 3 \mathrm{~N} 2$} & $\begin{array}{l}{[A, A, A, 3 A, A, 2 A,} \\
B, 1 A]\end{array}$ & $\begin{array}{l}\text { Reassortant by } \mathrm{H} 1 \mathrm{~N} 1 \\
\& \mathrm{H} 3 \mathrm{~N} 2 ?^{d}\end{array}$ & 1 & 1968 & {$[A, D, B, 3 A, A, 2 A, A, 1 A]$} & Reassortant by $\mathrm{H} 3 \mathrm{~N} 2$ \& CS & 1 & 2002 \\
\hline & $\begin{array}{l}{[C, D, E, 3 A, A, 2 A,} \\
A, 1 A]\end{array}$ & $\begin{array}{l}\text { Transmission from } \\
\text { TRIG [38] }\end{array}$ & 1 & 2005 & {$[F, G, I, 3 A, A, 2 A, F, 1 A]$} & Reassortant by EA \& CS [56] & 1 & 2004 \\
\hline & $\begin{array}{l}{[F, G, I, 3 A, F, 2 A,} \\
F, 1 E]\end{array}$ & $\begin{array}{l}\text { Transmission from EA } \\
{[57]}\end{array}$ & 1 & 1999 & & & & \\
\hline $\mathrm{H} 3 \mathrm{~N} 3$ & & & & & {$[C, F, E, 3 C, H, 3 A, E, 1 D]$} & Transmission from avian [48] & 2 & 2001 \\
\hline $\mathrm{H} 3 \mathrm{~N} 8$ & & & & & {$[C, I, G, 3 F, C, 8 B, E, 1 D]$} & Transmission from avian [58] & 2 & 2005-2006 \\
\hline H4N6 & & & & & {$[C, F, E, 4 A, H, 6 A, E, 1 D]$} & Transmission from avian [59] & 1 & 1999 \\
\hline
\end{tabular}


Table 2 Transmission and reassortment events of human and swine influenza A viruses (Continued)

\begin{tabular}{|c|c|c|c|c|c|c|c|c|}
\hline H5N1 & $\begin{array}{c}{[G, G, E, 5 J, F, 1 G,} \\
F, 1 E]\end{array}$ & $\begin{array}{l}\text { Transmission from } \\
\text { avian }[11,60]\end{array}$ & 13 & 1997-1998 & {$[K, G, D, 5 J, F, 1 J, F, 1 E]$} & Transmission from avian [61] & 9 & 2001-2004 \\
\hline & $\begin{array}{l}{[K, G, D, 5 J, F, 1 J} \\
F, 1 E]\end{array}$ & $\begin{array}{l}\text { Transmission from } \\
\text { avian }[10,62,63]\end{array}$ & 147 & $2003-2008$ & & & & \\
\hline & $\begin{array}{l}{[L, G, D, 5 J, F, 1 J} \\
F, 1 E]\end{array}$ & $\begin{array}{l}\text { Transmission from } \\
\text { avian }\end{array}$ & 1 & $2006(3)$ & & & & \\
\hline \multirow[t]{2}{*}{$\mathrm{H} 5 \mathrm{~N} 2$} & & & & & {$[C, G, E, 5 H, A, 2 D, A, 2 A]$} & $\begin{array}{l}\text { Reassortant by TRIG \& avian } \\
{[64]}\end{array}$ & 1 & 2008 \\
\hline & & & & & {$[G, G, D, 5 H, F, 2 D, F, 2 A]$} & Transmission from avian [64] & 1 & 2008 \\
\hline H7N3 & $\begin{array}{c}{[C, F, E, 7 F, H, 3 A} \\
E, 1 D]\end{array}$ & $\begin{array}{l}\text { Transmission from } \\
\text { avian [65] }\end{array}$ & 1 & 2004 & & & & \\
\hline H7N7 & $\begin{array}{c}{[G, G, D, 7 A, F, 7 D,} \\
F, 1 E]\end{array}$ & $\begin{array}{l}\text { Transmission from } \\
\text { avian [66] }\end{array}$ & 1 & 2003 & & & & \\
\hline \multirow[t]{3}{*}{ H9N2 } & $\begin{array}{c}{[G, G, D, 9 C, F, 2 B} \\
F, 1 E]\end{array}$ & $\begin{array}{l}\text { Transmission from } \\
\text { avian [67] }\end{array}$ & 1 & 2003 & {$[G, G, D, 9 F, F, 2 D, F, 1 E]$} & Transmission from avian & 1 & 2004 \\
\hline & $\begin{array}{c}{[\mathrm{G}, \mathrm{G}, \mathrm{E}, 9 \mathrm{C}, \mathrm{F}, 2 \mathrm{~B}} \\
\mathrm{F}, 1 \mathrm{E}]\end{array}$ & $\begin{array}{l}\text { Transmission from } \\
\text { avian [68] }\end{array}$ & 1 & 1999 & {$[\mathrm{~K}, \mathrm{G}, \mathrm{E}, 9 \mathrm{C}, \mathrm{F}, 2 \mathrm{~B}, \mathrm{~F}, 1 \mathrm{E}]$} & Transmission from avian [69] & 11 & 1998-2005 \\
\hline & $\begin{array}{c}{[\mathrm{G}, \mathrm{G}, \mathrm{E}, 9 \mathrm{~B}, \mathrm{~F}, 2 \mathrm{E},} \\
F, 1 \mathrm{E}]\end{array}$ & $\begin{array}{l}\text { Transmission from } \\
\text { avian [60] }\end{array}$ & 2 & 1999 & & & & \\
\hline \multicolumn{9}{|c|}{$\begin{array}{l}\text { aEvents: possible transmission or reassortment events and most of them were previously reported. CS: classic swine; EA: Eurasian avian-like swine; TRIG: Triple } \\
\text { reassortant swine. }\end{array}$} \\
\hline \multicolumn{9}{|c|}{${ }^{\mathrm{b}} \mathrm{N} .:$ the number of the relevant virus strains in FluGenome. } \\
\hline \multicolumn{9}{|c|}{$\begin{array}{l}\text { 'Year: the isolation year of the relevant virus strains in FluGenome. If multiple strains have been isolated, the first and the last years are listed. The numbers in } \\
\text { the round brackets following the years refer to some special virus strains in history: (1) A/Brevig Mission/1/1918; (2) A/New Jersey/1976; (3) A/Indonesia/CDC759/ } \\
\text { 2006; (4) A/swine/1931; (5) A/swine/Ohio/23/1935. }\end{array}$} \\
\hline
\end{tabular}

\section{Comparing swine reassortment patterns with previous work}

Rabadan et al. proposed a distance-based statistical method to analyze the reassortment phenomena and applied the method to human and swine influenza A viruses [13]. We collected the strain names of swine viruses from their paper and retrieved their genotypes from FluGenome. A/swine/Miyazaki/1/2006 was not included in the genotype database of FluGenome, and its genotype was determined manually by collecting its relevant genomic sequences from NCBI. A/swine/North Carolina/35922/98's genotype was not determined because of the lack of its entire genome sequence. The genotypes were further used to detect the potential reassortment events by our genotype profile method as described above.

\section{Results and Discussion}

Genotype profiles and patterns for human, swine and avian influenza $A$ viruses

\section{Human}

Genotype profiles for human, swine and avian influenza A viruses are listed in Table 1 . Corresponding to the classic or predominant virus strains in history and in recent influenza seasons, there are four basic genotypes for human influenza $A$ viruses: $[A, A, A / B, 1 B, A, 1 A, B$, $1 \mathrm{~A}]$ and $[\mathrm{C}, \mathrm{D}, \mathrm{E}, 1 \mathrm{~A}, \mathrm{~A}, 1 \mathrm{~F}, \mathrm{~F}, 1 \mathrm{~A}]$ for subtype $\mathrm{H} 1 \mathrm{~N} 1$ as well as $[\mathrm{A}, \mathrm{E}, \mathrm{B}, 2 \mathrm{~A}, \mathrm{~A}, 2 \mathrm{~A}, \mathrm{~B}, 1 \mathrm{~A}]$ for $\mathrm{H} 2 \mathrm{~N} 2$ and $[\mathrm{A}$, $\mathrm{D}, \mathrm{B}, 3 \mathrm{~A}, \mathrm{~A}, 2 \mathrm{~A}, \mathrm{~B}, 1 \mathrm{~A}]$ for H3N2. This means that the genotypes of most dominant circulating $\mathrm{H} 3 \mathrm{~N} 2$ viruses belong to $[\mathrm{A}, \mathrm{D}, \mathrm{B}, 3 \mathrm{~A}, \mathrm{~A}, 2 \mathrm{~A}, \mathrm{~B}, 1 \mathrm{~A}]$, with $\mathrm{PB} 2$ lineage $A, P B 1$ lineage $D, P A$ lineage $B, H A$ subtype 3 lineage A, NP lineage A, NA subtype 2 lineage A, MP lineage B and NS subtype 1 lineage A. The genotype nomenclature system consists of all eight gene segments, rather than serotypes of hemagglutinin and neuraminidase alone. Thus, the status of the whole virus genome is clearly reflected by the combination of the lineages of eight gene segments.

With the help of the genotypes, we could reconstruct the evolutionary history of the human influenza A virus. In 1918, a global pandemic was caused by the influenza A virus subtype $\mathrm{H} 1 \mathrm{~N} 1$. Taubenberger et al. isolated and sequenced a virus strain named A/Brevig Mission/1/ 1918, which had the genotype [A, A, A, 1A, A, 1A, B, 
1A] (see Table 2). They proposed that the virus was originally transmitted from avian host and adapted to human before the 1918 pandemic $[1,2,17,18]$ while some researchers argued that the evidence for the avian-origin hypothesis was not enough and it might be the result of a reassortment or a recombination between human and swine viruses [19-22]. It's hard to solve the debate exactly due to the lack of sampling viruses dominating in that era and the factors such as constraining selection and reassortment/recombination complicates phylogenetic analysis [19-24]. Regardless of its origin debate, the H1N1 virus varied quickly and caused the subsequent seasonal epidemics [1,2]. During the 1930s and 1940s (the sampling time of strains in FluGenome was 1933-1947), the genotype [A, A, A, 1B, A, 1A, B, 1A], which had a different HA lineage, dominated. In the next decade (the sampling time of strains in FluGenome was 1948-1957), nearly all circulating strains were [A, A, B, 1B, A, 1A, B, 1A], a strain that reappeared in 1977 and remained up to date. In 1957, three avian gene segments (PB1, HA and NA) replaced the corresponding human-adapted segments of influenza A (H1N1) [1,2], and a novel subtype $\mathrm{H} 2 \mathrm{~N} 2$ with genotype $[\mathrm{A}, \mathrm{E}, \mathrm{B}, 2 \mathrm{~A}$, A, 2A, B, 1A] was produced. In 1968, similar events occurred and led to the new H3N2 reassortant with genotype $[\mathrm{A}, \mathrm{D}, \mathrm{B}, 3 \mathrm{~A}, \mathrm{~A}, 2 \mathrm{~A}, \mathrm{~B}, 1 \mathrm{~A}]$, where $\mathrm{PB} 1$ and HA were derived from avian strains $[1,2]$.

\section{Swine}

Swine influenza A viruses can be classified into classic swine, Eurasian avian-like swine and triple-reassortant swine viruses. Classic swine influenza viruses have the genotype $[\mathrm{B}, \mathrm{A}, \mathrm{C}, 1 \mathrm{~A}, \mathrm{~A}, 1 \mathrm{~B}, \mathrm{~A}, 1 \mathrm{~A}]$ and only exist in the subtype H1N1. Because of divergence over long periods of time, the differences between the genotypes of human and classic swine influenza viruses (i.e., subtype H1N1) are large, and only the lineages for PB1, NP and NS are concordant. Around 1980, avian-like swine influenza A viruses appeared in Europe [25] and then appeared in Asia [26], replacing almost all of the previously predominant classic swine viruses $[27,28]$. The avian-like viruses have the genotype pattern $[F, G, I, 4$, $F, 6, F, 1 E]$, which is entirely different from the patterns for classic swine or human viruses. Furthermore, some gene segments, such as PB1 (lineage G), NP (lineage F), MP (lineage F) and NS (lineage 1E), are similar to segments that are conserved in avian viruses. It is also notable that the swine viruses that are subtype $\mathrm{H} 3 \mathrm{~N} 2$ have the same genotype, $[\mathrm{A}, \mathrm{D}, \mathrm{B}, 3 \mathrm{~A}, \mathrm{~A}, 2 \mathrm{~A}, \mathrm{~B}, 1 \mathrm{~A}]$, as the human viruses. In fact, the swine genotype was transmitted from humans, and the genome sequences of the human and swine H3N2 subtypes were highly homologous to date [29,30]. In 1998, the swine H3N2 virus reassorted with avian viruses and classic swine viruses to produce the novel triple reassortant with the genotype [C, D, E, 3A, A, 2A, A, 1A] [31,32]. The triple reassortants contain PB1 (lineage D), HA (lineage $3 \mathrm{~A}$ ), NP (lineage A), NA (lineage 2A) and NS (lineage 1A) from human H3N2 viruses; PB2 (lineage C) and PA (lineage E) from avian viruses and MP (lineage A) from classic swine viruses. The reassortants spread to subtypes $\mathrm{H} 1 \mathrm{~N} 1$ and $\mathrm{H} 1 \mathrm{~N} 2$ via reassortment with classic swine H1N1 viruses and, occasionally, with human H1N1 viruses [33,34]. In April 2009, the first global pandemic in the 21st century broke out in Mexico and the USA, eventually forcing the WHO to increase the pandemic level to the final alert phase (phase 6). The pandemic was caused by a new reassortant originating from swine with the genotype [C, D, E, 1A, A, 1F, F, 1A] . Most of the gene segments of the 2009 S-OIV emerged from the triple-reassortant viruses (i.e., subtype H1N1), whereas NA (lineage 1F) and MP (lineage F) were derived from a Eurasian avian-like swine virus (i.e., subtype H1N1). This is an entirely new genotype that has not been previously observed, although a very similar genotype, $[\mathrm{C}, \mathrm{D}, \mathrm{E}, 1 \mathrm{C}, \mathrm{A}, 1 \mathrm{~F}, \mathrm{~F}, 1 \mathrm{~A}]$, was found in a swine virus isolated in China in Jan, 2010 (see Table 2) [35]. The latter was also reassorted from triple-reassortant swine viruses isolated in China in 2006 and Eurasian avian-like swine viruses in China, where the avian-like swine viruses provided HA (lineage 1C), NA (lineage 1F) and MP (lineage F). This further confirmed the inference that 2009 S-OIV was first produced about ten years ago.

\section{Avian}

Because avian species, including waterfowl and domestic poultry, are natural reservoirs for influenza viruses, genetic diversity is abundant and various genotypes are present in avian hosts, especially in waterfowl. Nevertheless, distinct patterns in the genotypes of avian species were clearly observed: $[\mathrm{C}, \mathrm{F}, \mathrm{E} / \mathrm{H}, 4, \mathrm{H}, 6, \mathrm{E}, 1 \mathrm{D} / 2 \mathrm{~B}]$ for waterfowl and $[\mathrm{K} / \mathrm{G}, \mathrm{G}, \mathrm{D} / \mathrm{E}, 4, \mathrm{~F}, 6, \mathrm{~F}, 1 \mathrm{E} / 1 \mathrm{~F} / 2 \mathrm{~A}]$ for domestic poultry (see Table 1 and Additional file 1, Table S1). Additional file 1, Table S1 shows genotypes and typical hosts for multiple subtypes of waterfowl and domestic poultry. For example, waterfowl such as mallard ducks and green-winged teals mainly have the waterfowl genotype pattern regardless of their serotypes. Interestingly, the domestic poultry genotype was present in the viruses of subtype H5N1 isolated from mallards. This may have been the result of bi-directional virus exchange $[10,36]$. Similarly, most genotypes of chicken and duck viruses maintain the domestic poultry genotype pattern, whereas some of the viruses have waterfowl genotypes.

\section{Conserved lineages and genotype codes}

From genotype profiles, various conserved lineages of genotypes could be observed (see Table 1). For example, lineage A for PB2 is conserved in human $\mathrm{H} 1 \mathrm{~N} 1$ viruses, whereas lineage $\mathrm{B}$ is conserved in classic swine, lineage 
$\mathrm{C}$ is conserved in waterfowl and lineage $\mathrm{K} / \mathrm{G}$ is conserved in domestic poultry. It is not surprising that lineage $\mathrm{C}$ for $\mathrm{PB} 2$ could be found in triple-reassortant swine viruses and 2009 S-OIV because PB2 of these viruses emerged from avian viruses. We found that lineage $\mathrm{H}$ for NP and lineage E/F for MP are both conserved in avian viruses. Thus, if the lineages for the first three gene segments of the viruses are used, we may define "genotype codes" for human, swine and avian viruses. $[\mathrm{B}, \mathrm{A}, \mathrm{C}]$ is the genotype code for classic swine viruses, whereas $[F, G, I]$ is for Eurasian avian-like swine viruses and $[C, D, E]$ is for triple-reassortant swine viruses. The genotype code $[\mathrm{A}, \mathrm{A} / \mathrm{D} / \mathrm{E}, \mathrm{A} / \mathrm{B}]$ for classic human viruses is somewhat complex due to their frequent reassortment. Actually, the dominant viruses of subtypes H1N1 and H3N2 have simple codes: [A, A, B] ([A, A, A] for H1N1 viruses in the 1930s and 1940s) and [A, D, B], respectively. It is not surprising that human $2009 \mathrm{~S}$ OIV has the same [C, D, E] code as the triple-reassortant swine viruses. Similarly, the genotype codes for avian viruses are $[\mathrm{C}, \mathrm{F}, \mathrm{E} / \mathrm{H}]$ and $[\mathrm{K} / \mathrm{G}, \mathrm{G}, \mathrm{D} / \mathrm{E}]$. Using genotype codes, it becomes easy to classify candidate viruses. If the genotype code for a virus is [C, D, E], it is likely a triple-reassortant swine virus or human derivative like 2009 S-OIV. Similarly, it is obvious that [F, G, I] is Eurasian avian-like swine influenza A virus.

\section{Detecting transmission and reassortment events}

Table 2 lists the potential transmission and reassortment events of human and swine influenza A viruses that belong to rare genotypes when genotype profiles are constructed. For example, the virus strain A/Brevig Mission/1/1918 (genotype [A, A, A, 1A, A, 1A, B, 1A]) is the oldest influenza virus that has been sequenced and was proposed to be transmitted from avian species [17]. There are many avian genotypes in human and swine viruses, with serotypes varying from $\mathrm{H} 5 \mathrm{~N} 1$ to $\mathrm{H} 9 \mathrm{~N} 2$, all of which are the result of direct transmission across hosts. Bastien et al. isolated three strains (genotype [C, $\mathrm{D}, \mathrm{E}, 1 \mathrm{~B}, \mathrm{~A}, 1 \mathrm{~A}, \mathrm{~A}, 1 \mathrm{~A}]$ ) in Canada that were the products of genetic reassortment between seasonal H1N1 and triple-reassortant influenza viruses [37]. The genotype of 2009 S-OIV, [C, D, E, 1A, A, 1F, F, 1A] (see Table 1), consists of gene segments that originate from the triple-reassortant virus, subtype H1N1 (genotype [C, D, E, 1A, A, 1B, A, 1A]), and Eurasian avian-like swine virus, subtype H1N1 (genotype [F, G, I, 1C, F, 1F, F, $1 E])$. Transmission and reassortment events are common for subtype H1N1 swine viruses, probably due to the co-occurrence of classic swine, avian-like swine and triple-reassortant swine viruses and swine is the intermediate host for reassortment. Reassortment between triple-reassortant swine or avian-like swine viruses with classic swine (H1N1) or human H1N1 viruses can all be observed. For avian species, transmission events across hosts also occur. The Avian Influenza Virus Sequencing Project operated by the USDA Agriculture Research Service reported transmission events of classic swine viruses (genotype $[\mathrm{B}, \mathrm{A}, \mathrm{C}, 1 \mathrm{~A}, \mathrm{~A}, 1 \mathrm{~B}, \mathrm{~A}, 1 \mathrm{~A}]$ ) and triple-reassortant swine viruses (genotype $[\mathrm{C}, \mathrm{D}, \mathrm{E}, 3 \mathrm{~A}, \mathrm{~A}$, $2 \mathrm{~A}, \mathrm{~A}, 1 \mathrm{~A}]$ ), most of which were transmitted from swine to turkeys (data not shown). The latter was also confirmed by Olsen et al. in Canada [38]. Because avian viruses have complex genotypes and abundant genetic diversity, it is difficult to trace transmission and reassortment events among avian species. However, it is still possible to infer potential cases of transmission and reassortment between waterfowl and domestic poultry because their genotype patterns are different.

Comparing swine reassortment patterns with previous work Table 3 lists the reassortment events in swine influenza A viruses detected by Rabadan's method [13] in the left part of the table. Most gene segments have one of the two swine-origin lineages (S1 and S2) except for some lineages being avian (A) or human $(\mathrm{H})$ derived. Due to the mixed lineages of S1 and S2, the gene segments may be the result of reassortment. To our surprise, we found that most of the virus strains belonged to the classic swine, triple-reassortant swine and Eurasian avian-like swine virus groups when the results of the genotype profile method were analyzed. Rabadan's distance-based method was based on such a rule: the nucleotide differences at the third codon position between two segments of two strains should be proportional if the two segments have a common origin. A violation of this rule indicates that the co-occurrence of two segments may be the result of reassortment events. The rule will experience problems when the reference strains and segments for swine viruses are not selected carefully. For example, if a classic swine strain is set as the reference strain, then all triple-reassortant viruses will be classified as reassortants because some segments originate from classic swine viruses, whereas others do not. With regard to Eurasian avian-like swine viruses, which have no shared segments with the classic swine virus, their classification results would be uncertain and dependent on paired nucleotide differences. If the differences are proportional by chance, the viruses would be classified as descendants from the reference strain, or they may be classified as reassortants. For example, two Eurasian avian-like swine viruses (A/swine/Italy/1521/98 and A/ swine/Cloppenburg/IDT4777/2005) with the genotype [F, G, I, 1B, F, 2A, F, 1E] are considered to have all classic swine lineages by Rabadan's method, whereas our method regards them as basic genotypes for Eurasian avian-like swine viruses that were possibly reassorted from Eurasian avian-like and triple-reassortant swine viruses $[39,40]$. Another example, consider A/Swine/ Indiana/9K035/99 and A/Swine/Minnesota/55551/00, 
Table 3 Comparing reassortment patterns in swine influenza A viruses with Rabadan's method

\begin{tabular}{|c|c|c|c|c|c|c|c|c|c|c|c|c|c|}
\hline Year & & Rabadan' & $s$ met & hod & & & & & & & Genotype pr & ofile method & Ref. $^{a}$ \\
\hline & Strain & Subtype & PB2 & PB1 & PA & HA & NP & NA & MP & NS & Genotype & Classification & \\
\hline 1976 & A/swine/lowa/1/1976 & H1N1 & S1 & S2 & S1 & S1 & S1 & S1 & S1 & S1 & {$[B, A, C, 1 A, A, 1 B, A, 1 A]$} & Classic swine & \\
\hline 1976 & A/swine/Tennessee/15/1976 & $\mathrm{H} 1 \mathrm{~N} 1$ & S1 & S2 & S1 & S1 & S1 & S1 & S1 & S1 & {$[B, A, C, 1 A, A, 1 B, A, 1 A]$} & Classic swine & \\
\hline 1976 & A/swine/Tennessee/19/1976 & H1N1 & S1 & S1 & S1 & S1 & S1 & S1 & S2 & S1 & {$[B, A, C, 1 A, A, 1 B, A, 1 A]$} & Classic swine & \\
\hline 1976 & A/swine/Tennessee/23/1976 & H1N1 & S1 & S2 & S1 & S1 & S1 & S1 & S1 & S1 & {$[B, A, C, 1 A, A, 1 B, A, 1 A]$} & Classic swine & \\
\hline 1977 & A/swine/Tennessee/48/1977 & H1N1 & S1 & S1 & S2 & S1 & S1 & S1 & S2 & S1 & {$[B, A, C, 1 A, A, 1 B, A, 1 A]$} & Classic swine & \\
\hline 1977 & A/swine/Tennessee/61/1977 & H1N1 & S1 & S1 & S1 & S1 & S1 & S1 & S2 & S1 & {$[B, A, C, 1 A, A, 1 B, A, 1 A]$} & Classic swine & \\
\hline 1977 & A/swine/Tennessee/62/1977 & $\mathrm{H} 1 \mathrm{~N} 1$ & S1 & S1 & S1 & S1 & S1 & S2 & S2 & S1 & {$[B, A, C, 1 A, A, 1 B, A, 1 A]$} & Classic swine & \\
\hline 1977 & A/swine/Tennessee/64/1977 & H1N1 & S1 & S2 & S1 & S1 & S1 & S1 & S1 & S1 & {$[B, A, C, 1 A, A, 1 B, A, 1 A]$} & Classic swine & \\
\hline 1977 & A/swine/Tennessee/82/1977 & H1N1 & S1 & S1 & S1 & S2 & S1 & S2 & S1 & S1 & {$[B, A, C, 1 A, A, 1 B, A, 1 A]$} & Classic & \\
\hline 1977 & A/swine/Tennessee/96/1977 & H1N1 & S1 & S1 & S1 & S1 & S1 & S1 & S1 & S2 & {$[B, A, C, 1 A, A, 1 B, A, 1 A]$} & Classic swine & \\
\hline 1979 & $\begin{array}{l}\text { A/swine/Minnesota/5892-7/ } \\
1979\end{array}$ & H1N1 & S1 & S1 & S1 & S1 & S2 & S1 & S1 & S1 & {$[B, A, C, 1 A, A, 1 B, A, 1 A]$} & Classic swine & \\
\hline 1981 & A/swine/Ontario/6/1981 & H1N1 & S1 & S1 & S1 & S1 & $\mathrm{S} 2$ & S1 & S1 & S1 & {$[B, A, C, 1 A, A, 1 B, A, 1 A]$} & Classic swine & \\
\hline 1986 & A/swine/lowa/1/1986 & H1N1 & S1 & S1 & S2 & S2 & S1 & S1 & S1 & S1 & {$[B, A, C, 1 A, A, 1 B, A, 1 A]$} & Classic swine & \\
\hline 1988 & A/swine/Wisconsin/1915/1988 & & S1 & S1 & S1 & S1 & S2 & S1 & S1 & S1 & & Clas & \\
\hline 2004 & A/swine/Korea/CAN01/2004 & $\mathrm{H} 1 \mathrm{~N} 1$ & S1 & S1 & S1 & S1 & S1 & S2 & S1 & S1 & {$[C, D, E, 1 A, A, 1 B, A, 1 A]$} & Triple-reassortant swine & [25] \\
\hline 004 & A/swine/Spain/53207/2004 & H1N1 & S1 & S1 & S1 & S2 & S1 & S2 & S1 & S3 & {$[F, G, I, 1 C, F, 1 F, F, 1 E]$} & Eurasian avian-like swine & \\
\hline 2007 & A/swine/Ohio/24366/07 & H1N1 & S1 & S1 & S1 & S2 & S1 & S2 & S1 & S1 & {$[C, D, E, 1 A, A, 1 B, A, 1 A]$} & Triple-reassortant swine & \\
\hline 1998 & A/swine/Italy/1521/98 & $\mathrm{H} 1 \mathrm{~N} 2$ & S1 & S1 & S1 & S2 & S1 & S3 & S1 & S1 & {$[F, G, I, 1 B, F, 2 A, F, 1 E]$} & Eurasian avian-like swine & [18] \\
\hline 1999 & A/Swine/Indiana/9K035/99 & $\mathrm{H} 1 \mathrm{~N} 2$ & S1 & S1 & S1 & S2 & S1 & S1 & S1 & S1 & {$[C, D, E, 1 A, A, 2 A, A, 1 A]$} & Triple-reassortant swine & [36] \\
\hline 2000 & A/Swine/Minnesota/55551/00 & $\mathrm{H} 1 \mathrm{~N} 2$ & S1 & S1 & S1 & S2 & S1 & S1 & S1 & S1 & {$[C, D, E, 1 A, A, 2 A, A, 1 A]$} & Triple-reassortant swine & [37] \\
\hline 2004 & A/swine/Zhejiang/1/2004 & $\mathrm{H} 1 \mathrm{~N} 2$ & S1 & S1 & S1 & S1 & S1 & $\mathrm{H}$ & S1 & S1 & {$[B, A, C, 1 A, A, 2 A, A, 1 A]$} & $\begin{array}{l}\text { Reassortant by classic \& } \\
\text { H3N2 }\end{array}$ & [19] \\
\hline 2005 & $\begin{array}{l}\text { A/swin } \\
\text { IDT477 }\end{array}$ & $\mathrm{H} 1 \mathrm{~N} 2$ & S1 & S1 & S1 & S1 & S1 & S2 & S1 & S1 & {$[F, G, I, 1 B, F, 2 A, F, 1 E]$} & Eurasian avian-like swine & [20] \\
\hline 2006 & A/swine/Miyazaki/1/2006 & H1N2 & S1 & S1 & S1 & S1 & S1 & S3 & S1 & S1 & {$[B, A, C, 1 A, A, 2 A, A, 1 A]$} & $\begin{array}{l}\text { Reassortant by classic \& } \\
\text { H3N2 }\end{array}$ & {$[21]$} \\
\hline 2007 & A/swine/Shanghai/1/2007 & $\mathrm{H} 1 \mathrm{~N} 2$ & S1 & S1 & S1 & $\mathrm{S} 2$ & S1 & S1 & S1 & S1 & {$[C, D, E, 1 A, A, 2 A, A, 1 A]$} & Triple-reassortant swine & \\
\hline 1998 & A/Swine/Nebraska/209/98 & $\mathrm{H} 3 \mathrm{~N} 2$ & A & $\mathrm{H}$ & A & $\mathrm{H}$ & $S$ & $\mathrm{H}$ & $S$ & $S$ & {$[C, D, E, 3 A, A, 2 A, A, 1 A]$} & Triple-reassortant swine & {$[36]$} \\
\hline 2001 & A/swine/Spain/33601/2001 & $\mathrm{H} 3 \mathrm{~N} 2$ & S1 & S1 & S1 & $\mathrm{S} 2$ & S1 & S2 & S1 & S1 & {$[F, G, I, 3 A, F, 2 A, F, 1 E]$} & Eurasian avian-like swine & \\
\hline 2003 & A/swine/North Carolina/2003 & $\mathrm{H} 3 \mathrm{~N} 2$ & S & S & S & $\mathrm{H} 1$ & $S$ & $\mathrm{H} 2$ & S & S & {$[C, D, E, 3 A, A, 2 A, A, 1 A]$} & Triple-reassortant swine & \\
\hline 2007 & A/swine/Korea/CY04/2007 & $\mathrm{H} 3 \mathrm{~N} 2$ & S1 & S1 & S1 & S1 & S1 & S1 & S1 & S2 & {$[C, D, E, 3 A, A, 2 A, A, 1 A]$} & Triple-reassorta & {$[25]$} \\
\hline 2007 & A/swine/Korea/CY07/2007 & $\mathrm{H} 3 \mathrm{~N} 2$ & S1 & S1 & S2 & S2 & S1 & S1 & S1 & S1 & {$[C, D, E, 3 A, A, 2 A, A, 1 A]$} & Triple-reassortant swine & [25] \\
\hline 1998 & $\begin{array}{l}\text { A/swine/North Carolina/ } \\
\text { 35922/98 }\end{array}$ & $\mathrm{H} 3 \mathrm{~N} 2$ & S & $\mathrm{H}$ & S & $\mathrm{H}$ & S & $\mathrm{H}$ & S & S & Unknown & & {$[16]$} \\
\hline 2004 & A/swine/MI/PU243/04 & $\mathrm{H} 3 \mathrm{~N} 1$ & S1 & S1 & S1 & S1 & S1 & S2 & S1 & S1 & {$[C, D, E, 3 A, A, 1 B, A, 1 A]$} & $\begin{array}{l}\text { Reassortant by triple \& } \\
\text { classic }\end{array}$ & [38] \\
\hline 2006 & $\begin{array}{l}\text { A/swine/Missouri/2124514/ } \\
2006\end{array}$ & $\mathrm{H} 2 \mathrm{~N} 3$ & S1 & S2 & A & A & S1 & A & S1 & S1 & {$[C, D, E, 2 H, A, 3 A, A, 1 A]$} & $\begin{array}{l}\text { Reassortant by triple \& } \\
\text { avian }\end{array}$ & [39] \\
\hline 2003 & A/swine/Alberta/56626/03 & H1N1 & S1 & S1 & S2 & S1 & S1 & S3 & S1 & S1 & {$[B, A, C, 1 A, A, 1 B, A, 1 A]$} & Classic swine & [40] \\
\hline 2003 & A/swine/Ontario/53518/03 & H1N1 & S3 & S3 & S2 & S1 & S3 & S1 & S1 & S1 & {$[C, D, C, 1 A, A, 1 B, A, 1 A]$} & $\begin{array}{l}\text { Reassortant by triple \& } \\
\text { classic }\end{array}$ & {$[40]$} \\
\hline 2003 & A/swine/Ontario/57561/03 & $\mathrm{H} 1 \mathrm{~N} 1$ & S1 & S1 & S2 & S1 & S3 & S1 & S2 & S1 & {$[B, A, C, 1 A, A, 1 B, A, 1 A]$} & Classic swine & {$[40]$} \\
\hline 2004 & A/swine/Ontario/48235/04 & $\mathrm{H} 1 \mathrm{~N} 2$ & S1 & $\mathrm{H} 1$ & S1 & $\mathrm{H} 2$ & $\mathrm{~S} 2$ & $\mathrm{H} 3$ & S3 & S3 & {$[B, D, C, 1 B, A, 2 A, A, 1 A]$} & $\begin{array}{l}\text { Reassortant by triple \& } \\
\text { classic }\end{array}$ & [40] \\
\hline 2004 & A/swine/Ontario/11112/04 & $\mathrm{H} 1 \mathrm{~N} 1$ & S1 & $\mathrm{H}$ & S1 & S1 & S2 & S1 & S1 & S1 & {$[B, D, C, 1 A, A, 1 B, A, 1 A]$} & $\begin{array}{l}\text { Reassortant by triple \& } \\
\text { classic }\end{array}$ & [40] \\
\hline 2005 & A/swine/Alberta/14722/2005 & $\mathrm{H} 3 \mathrm{~N} 2$ & $S$ & S & S & $S$ & $S$ & $\mathrm{H}$ & $S$ & S & {$[C, D, E, 3 A, A, 2 A, A, 1 A]$} & Triple-reassortant swine & [41] \\
\hline
\end{tabular}

${ }^{\text {a}}$ Ref. numbers refer to citations used in Rabadan's paper [14] 


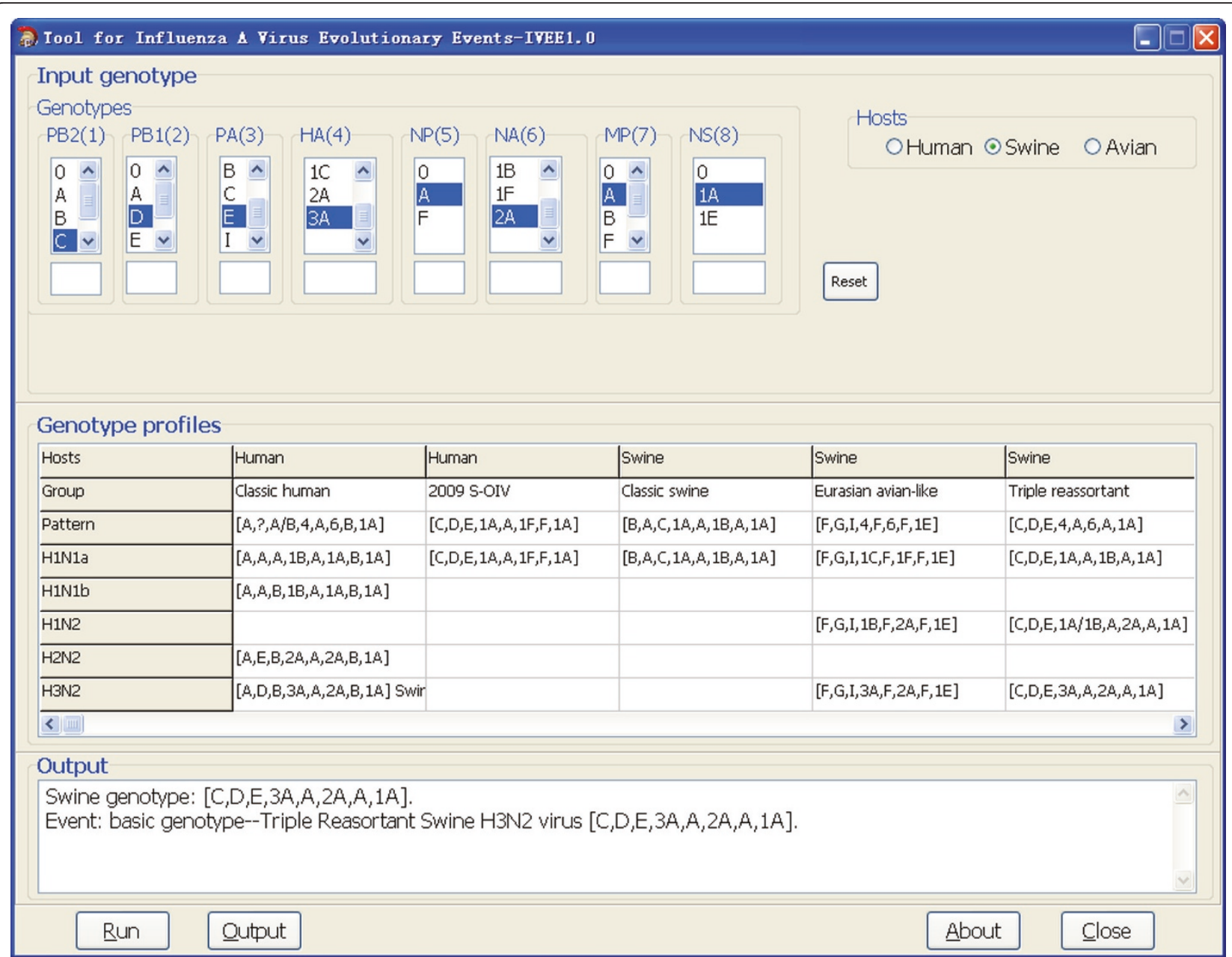

Figure 2 Screenshot of IVEE.

which were reported to be new triple-reassortant swine viruses by Karasin et al [41]. However, Rabadan assumed that all gene segments except HA had the same lineages as classic swine. In fact, the H1N2 reassortant viruses were derived from traditional H3N2 triple reassortants and H1N1 classic swine viruses. Phylogenetic analysis confirmed the results of genotype profile method (see Additional file 1, Table S2 and Additional file 1, Figure S1). These examples show that our method is easy to use and accurate for analyzing reassortment process, whereas the distance-based method has difficulty dealing with complex situations, although it does work in certain cases. In our opinion, genotypes of triple-reassortant and Eurasian avian-like swine viruses in genotype profiles can be considered transmission and reassortment events. Thus, genotypes such as $[\mathrm{B}, \mathrm{A}, \mathrm{C}, 1 \mathrm{~A}, \mathrm{~A}, 2 \mathrm{~A}, \mathrm{~A}, 1 \mathrm{~A}]$ and $[\mathrm{C}, \mathrm{D}, \mathrm{E}, 2 \mathrm{H}, \mathrm{A}$, $3 \mathrm{~A}, \mathrm{~A}, 1 \mathrm{~A}]$ are true reassortants that can be determined by genotype profiles. However, for H1N1 strains belonging to the classic swine viruses, the genotype profile method could not identify whether they are reassortants because our method has difficulty inferring intra-subtype reassortment events within the same host, as will be discussed below.

The greatest advantage of the genotype profile is that it is a straightforward method following the real viral reassortment process. In fact, the phylogenetic analysis process is hidden under the definition and construction of genotypes [14]. As shown in Figure 1, lineages were defined as significant clusters (about 10\% nucleotide difference by p-distance) in phylogenetic trees constructed by all viruses with full genomic sequences. There is no need to reconstruct the phylogenetic trees as long as the shape of the trees has not changed due to epidemiology and no novel lineage needs to be assigned. The determination of genotypes is then performed by finding a position for the virus in the established trees using a BLAST algorithm. The genotype profile method takes advantage of the phylogenetic algorithms' inferring from sequences, integrates epidemiology knowledge into genotype profiles 
and keeps the epidemiological interfaces for the users to assemble.

An application (see Figure 2) called "Analysis Tool for Influenza A Virus Evolutionary Events (IVEE)" that implements genotype profile method is available for all academic users from the website http://snptransformer. sourceforge.net. In current version, the genotype profiles as shown in Table 1 are embedded and fixed in the program by the authors. The custom genotype profile function will be implemented in the next version, which allows the users to edit the genotype profiles to satisfy various research demands such as updating the newlydiscovered genotypes and studying the historic reassortment events. Furthermore, each genotype will be associated with a representative virus strain to help read the analysis results.

The genotype profile based method still had limitations when inferring intra-subtype reassortment within the same host. For example, nearly all human H3N2 viruses have the genotype $[\mathrm{A}, \mathrm{D}, \mathrm{B}, 3 \mathrm{~A}, \mathrm{~A}, 2 \mathrm{~A}, \mathrm{~B}, 1 \mathrm{~A}]$, which restrains distinguishing intra-subtype reassortment events as Holmes [5] and Nelson have done [6]. The reason is that a cutoff of a $10 \%$ nucleotide difference by p-distance for defining lineages in the phylogenetic tree is too coarse to distinguish some virus clades among subtypes, although it is sufficient for inter-subtype reassortment. One possible solution is to define clades under lineages by FluGenome with lower cutoffs such as $1 \%$. In fact, the WHO/OIE/FAO H5N1 Evolution Working Group has developed a web tool for HPAI H5N1 HA clade prediction http://h5n1.flugenome.org based on FluGenome with average distances of $\geqq 1.5 \%$ between clades. The tool and its unified nomenclature system for the HA clade designation of HPAI H5N1 viral strains were used later to facilitate resolution of the nomenclature problem and to make comparisons among virus clades easier across publications. However, the clade designation was designed only for HA without taking into account other gene segments. We suggest that a similar international committee should be established to assign unified clades for all segments of influenza A viruses. This will greatly help research and increase our knowledge of the evolutionary tendency of influenza A viruses.

\section{Conclusions}

In conclusion, we extended the concept of "genotype" to "genotype profile" to describe classic or dominant virus strains and constructed the genotype profiles for influenza A viruses of humans, swine and avian species. Genotype profiles not only decrease the complexity of combinations of hundreds of genotypes but also provide epidemiological information of influenza A viruses for the analysis. With genotype profile method, the analysis of reassortment and transmission events is a simple and reliable process that combines genotypes. We detected various transmission and reassortment events from rare genotypes stored in FluGenome and found that one previous summary of the reassortment events in swine influenza A viruses may be inaccurate. Using genotype profile method, surveillance for virus transmission and reassortment becomes straightforward and it's possible to setup an automatic surveillance system for detecting such evolutionary events.

\section{Additional material}

Additional file 1: Table S1. Genotype profiles for avian influenza A virus. Table S2. The results compared by phylogenetic analysis and genotype profile method. Figure S1. Phylogenetic trees for influenza A virus strains.

\section{Acknowledgements}

We thank two anonymous referees for their comments and suggestions. CD was supported by the National Natural Science Foundation of China (31000594), the Foundation of Zhejiang Province Educational Committee (Y200906182), the Hulan Scholar Fund and the K.C. Wong Magna Fund of Ningbo University.

\section{Authors' contributions}

CD conceived and designed the study. CD, LY and DY performed the study and drafted the manuscript. All authors read and approved the final manuscript.

\section{Competing interests}

The authors declare that they have no competing interests.

Received: 11 March 2011 Accepted: 9 August 2011

Published: 9 August 2011

\section{References}

1. Zimmer SM, Burke DS: Historical perspective - emergence of influenza A (H1N1) viruses. N Engl J Med 2009, 361:279-285.

2. Morens DM, Taubenberger JK, Fauci AS: The persistent legacy of the 1918 influenza virus. N Engl J Med 2009, 361:225-229.

3. Smith GJD, Vijaykrishna D, Bahl J, Lycett SJ, Worobey M, Pybus OG, Ma SK, Cheung $\mathrm{CL}$, Raghwani J, Bhatt $\mathrm{S}$, et al: Origins and evolutionary genomics of the 2009 swine-origin H1N1 influenza A epidemic. Nature 2009, 459:1122-1125.

4. Novel Swine-Origin Influenza A. Virus Investigation Team: Emergence of a novel swine-origin influenza $\mathrm{A}(\mathrm{H} 1 \mathrm{H} 1)$ virus in humans. $N$ Engl J Med 2009, 360:2605-2615.

5. Holmes EC, Ghedin E, Miller N, Taylor J, Bao Y, St George K, Grenfell BT, Salzberg SL, Fraser CM, Lipman DJ, Taubenberger JK: Whole-genome analysis of human influenza $A$ virus reveals multiple persistent lineages and reassortment among recent H3N2 viruses. PLoS Biol 2005, 3:e300.

6. Nelson MI, Viboud C, Simonsen L, Bennett RT, Griesemer SB, St. George K, Taylor J, Spiro DJ, Sengamalay NA, Ghedin E, et al: Multiple reassortment events in the evolutionary history of H1N1 influenza A virus since 1918. PLOS Pathog 2008, 4:e1000012.

7. Nelson MI, Edelman L, Spiro DJ, Boyne AR, Bera J, Halpin R, Ghedin E, Miller MA, Simonsen L, Viboud C, Holmes EC: Molecular epidemiology of $\mathrm{A} / \mathrm{H} 3 \mathrm{~N} 2$ and $\mathrm{A} / \mathrm{H} 1 \mathrm{~N} 1$ influenza virus during a single epidemic season in the United States. PLoS Pathog 2008, 4:e1000133.

8. Nelson MI, Simonsen L, Viboud C, Miller MA, Taylor J, George KS, Griesemer SB, Ghedin E, Sengamalay NA, Spiro DJ, et al: Stochastic processes are key determinants of short-term evolution in influenza $A$ virus. PLoS Pathog 2006, 2:e125.

9. Vijaykrishna D, Poon LLM, Zhu HC, Ma SK, Li OTW, Cheung CL, Smith GJD, Peiris JSM, Guan Y: Reassortment of pandemic H1N1/2009 influenza A virus in swine. Science 2010, 328:1529-1529. 
10. Li KS, Guan Y, Wang J, Smith GJD, Xu KM, Duan L, Rahardjo AP, Puthavathana P, Buranathai C, Nguyen TD, et al: Genesis of a highly pathogenic and potentially pandemic $\mathrm{H} 5 \mathrm{~N} 1$ influenza virus in eastern Asia. Nature 2004, 430:209-213.

11. Subbarao K, Klimov A, Katz J, Regnery H, Lim W, Hall H, Perdue M, Swayne D, Bender C, Huang J, et al: Characterization of an avian influenza A (H5N1) virus isolated from a child with a fatal respiratory illness. Science 1998, 279:393-396.

12. Rabadan R, Levine AJ, Krasnitz M: Non-random reassortment in human influenza A viruses. Influenza Other Respi Viruses 2008, 2:9-22.

13. Khiabanian $H$, Trifonov $V$, Rabadan R: Reassortment patterns in swine influenza viruses. PLOS ONE 2009, 4:e7366.

14. Lu G, Rowley T, Garten R, Donis RO: FluGenome: a web tool for genotyping influenza A virus. Nucl Acids Res 2007, 35:W275-279.

15. FluGenome. [http://www.flugenome.org].

16. Bao Y, Bolotov P, Dernovoy D, Kiryutin B, Tatusova T: FLAN: a web server for influenza virus genome annotation. Nucl Acids Res 2007, 35:W280-284.

17. Taubenberger JK, Reid AH, Lourens RM, Wang R, Jin G, Fanning TG: Characterization of the 1918 influenza virus polymerase genes. Nature 2005, 437:889-893.

18. Taubenberger JK, Reid AH, Krafft AE, Bijwaard KE, Fanning TG: Initial genetic characterization of the 1918 "spanish" influenza virus. Science 1997, 275:1793-1796.

19. Gibbs MJ, Armstrong JS, Gibbs AJ: Recombination in the Hemagglutinin Gene of the 1918 "Spanish Flu". Science 2001, 293:1842-1845.

20. Gibbs MJ, Gibbs AJ: Molecular virology: Was the 1918 pandemic caused by a bird flu? Nature 2006, 440:E8-E8.

21. Antonovics J, Hood ME, Baker CH: Molecular virology: Was the $1918 \mathrm{flu}$ avian in origin? Nature 2006, 440:E9-E9.

22. Vana G, Westover KM: Origin of the 1918 Spanish influenza virus: A comparative genomic analysis. Mol Phylogenet Evol 2008, 47:1100-1110.

23. Worobey M, Rambaut A, Pybus OG, Robertson DL, Gibbs MJ, Armstrong JS, Gibbs AJ: Questioning the Evidence for Genetic Recombination in the 1918 "Spanish Flu" Virus. Science 2002, 296:211-211.

24. Taubenberger JK, Reid AH, Lourens RM, Wang R, Jin G, Fanning TG: Molecular virology: Was the 1918 pandemic caused by a bird flu? Was the 1918 flu avian in origin? (Reply). Nature 2006, 440:E9-E10.

25. Scholtissek C, Bürger $H$, Bachmann PA, Hannoun C: Genetic relatedness of hemagglutinins of the $\mathrm{H} 1$ subtype of influenza a viruses isolated from swine and birds. Virology 1983, 129:521-523.

26. Guan Y, Shortridge KF, Krauss S, Li PH, Kawaoka Y, Webster RG: Emergence of avian H1N1 influenza viruses in pigs in China. J Virol 1996, 70:8041-8046.

27. Hinshaw VS, Alexander DJ, Aymard M, Bachmann PA, Easterday BC, Hannoun C, Kida H, Lipkind M, MacKenzie JS, Nerome K, et al: Antigenic comparisons of swine-influenza-like $\mathrm{H} 1 \mathrm{~N} 1$ isolates from pigs, birds and humans: an inter- national collaborative study. Bull WHO 1984, 62:871-878

28. Schultz U, Fitch WM, Ludwig S, Mandler J, Scholtissek C: Evolution of pig influenza viruses. Virology 1991, 183:61-73.

29. de Jong JC, Smith DJ, Lapedes AS, Donatelli I, Campitelli L, Barigazzi G, Van Reeth K, Jones TC, Rimmelzwaan GF, Osterhaus ADME, Fouchier RAM: Antigenic and genetic evolution of swine influenza $A(H 3 N 2)$ viruses in Europe. J Virol 2007, 81:4315-4322.

30. Yu H, Hua R-H, Zhang Q, Liu T-Q, Liu H-L, Li G-X, Tong G-Z: Genetic evolution of swine influenza A (H3N2) viruses in China from 1970 to 2006. J Clin Microbiol 2008, 46:1067-1075.

31. Zhou NN, Senne DA, Landgraf JS, Swenson SL, Erickson G, Rossow K, Liu L, Yoon K-j, Krauss S, Webster RG: Genetic reassortment of avian, swine, and human influenza A viruses in American pigs. J Virol 1999, 73:8851-8856.

32. Karasin Al, Schutten MM, Cooper LA, Smith CB, Subbarao K, Anderson GA, Carman S, Olsen CW: Genetic characterization of H3N2 influenza viruses isolated from pigs in North America, 1977-1999: evidence for wholly human and reassortant virus genotypes. Virus Res 2000, 68:71-85.

33. Olsen CW: The emergence of novel swine influenza viruses in North America. Virus Res 2002, 85:199-210.

34. Vincent AL, Ma W, Lager KM, Janke BH, Richt JA, Karl Maramorosch AJSaFAM: Swine influenza viruses: a North American perspective. In Adv Virus Res. Volume 72. Academic Press; 2008:127-154.

35. Xu M, Huang Y, Chen J, Huang Z, Zhang J, Zhu Y, Xie S, Chen Q, Wei W, Yang D, et al: Isolation and genetic analysis of a novel triple-reassortant H1N1 influenza virus from a pig in China. Vet Microbiol 2011, 147:403-409.
36. Li KS, Xu KM, Peiris JSM, Poon LLM, Yu KZ, Yuen KY, Shortridge KF, Webster RG, Guan Y: Characterization of H9 subtype influenza viruses from the ducks of Southern China: a candidate for the next influenza pandemic in humans? J Virol 2003, 77:6988-6994.

37. Bastien N, Antonishyn N, Brandt K, Wong C, Chokani K, Vegh N, Horsman G, Tyler S, Graham M, Plummer F, et al: Human infection with a triplereassortant swine influenza $\mathrm{A}(\mathrm{H} 1 \mathrm{~N} 1)$ virus containing the Hemagglutinin and Neuraminidase genes of seasonal influenza virus. J Infect Dis 2010, 201:1178-1182.

38. Olsen CW, Karasin Al, Carman S, Li Y, Bastien N, Ojkic D, Alves D, Charbonneau G, Henning BM, Low DE, et al: Triple reassortant H3N2 influenza A viruses, Canada, 2005. Emerg Infect Dis 2006, 12:1132-1135.

39. Zell R, Motzke S, Krumbholz A, Wutzler P, Herwig V, Durrwald R: Novel reassortant of swine influenza H1N2 virus in Germany. J Gen Virol 2008, 89:271-276.

40. Marozin S, Gregory V, Cameron K, Bennett M, Valette M, Aymard M, Foni E, Barigazzi G, Lin Y, Hay A: Antigenic and genetic diversity among swine influenza A H1N1 and H1N2 viruses in Europe. J Gen Virol 2002, 83:735-745.

41. Karasin Al, Olsen CW, Anderson GA: Genetic characterization of an H1N2 influenza virus isolated from a pig in Indiana. J Clin Microbiol 2000, 38:2453-2456

42. Yu H, Zhou Y-J, Li G-X, Zhang G-H, Liu H-L, Yan L-P, Liao M, Tong G-Z: Further evidence for infection of pigs with human-like H1N1 influenza viruses in China. Virus Res 2009, 140:85-90.

43. Gaydos JC, Top FH, Hodder RA, Russell PK: Swine Influenza A outbreak, Fort Dix, New Jersey, 1976. Emerg Infect Dis 2006, 12:23-28.

44. Dunham EJ, Dugan VG, Kaser EK, Perkins SE, Brown IH, Holmes EC, Taubenberger JK: Different evolutionary trajectories of European AvianLike and classical swine H1N1 influenza A viruses. J Virol 2009, 83:5485-5494.

45. Karasin Al, Carman S, Olsen CW: Identification of human H1N2 and human-swine reassortant H1N2 and H1N1 influenza A Viruses among pigs in Ontario, Canada (2003 to 2005). J Clin Microbiol 2006, 44:1123-1126.

46. Gray GC, McCarthy T, Capuano AW, Setterquist SF, Olsen CW, Alavanja MC: Swine workers and swine influenza virus infections. Emerg Infect Dis 2007, 13:1871-1878.

47. Vincent A, Ma W, Lager K, Gramer M, Richt J, Janke B: Characterization of a newly emerged genetic cluster of $\mathrm{H} 1 \mathrm{~N} 1$ and $\mathrm{H} 1 \mathrm{~N} 2$ swine influenza virus in the United States. Virus Genes 2009, 39:176-185.

48. Karasin Al, West K, Carman S, Olsen CW: Characterization of avian H3N3 and $\mathrm{H} 1 \mathrm{~N} 1$ influenza A viruses isolated from pigs in Canada. J Clin Microbiol 2004, 42:4349-4354.

49. Takemae N, Parchariyanon S, Damrongwatanapokin S, Uchida Y, Ruttanapumma R, Watanabe C, Yamaguchi S, Saito T: Genetic diversity of swine influenza viruses isolated from pigs during 2000 to 2005 in Thailand. Influenza Other Respi Viruses 2008, 2:181-189.

50. Ghedin E, Sengamalay NA, Shumway M, Zaborsky J, Feldblyum T, Subbu V, Spiro DJ, Sitz J, Koo H, Bolotov P, et al: Large-scale sequencing of human influenza reveals the dynamic nature of viral genome evolution. Nature 2005, 437:1162-1166

51. Bragstad K, Nielsen L, Fomsgaard A: The evolution of human influenza A viruses from 1999 to 2006: A complete genome study. Viro J 2008, 5:40

52. Qi X, Lu CP: Genetic characterization of novel reassortant H1N2 influenza A viruses isolated from pigs in southeastern China. Arch Virol 2006, 151:2289-2299.

53. Ma W, Vincent AL, Gramer MR, Brockwell CB, Lager KM, Janke BH, Gauger PC, Patnayak DP, Webby RJ, Richt JA: Identification of H2N3 influenza A viruses from swine in the United States. Proc Natl Acad Sci USA 2007, 104:20949-20954.

54. Shin J-Y, Song M-S, Lee EH, Lee Y-M, Kim S-Y, Kim HK, Choi J-K, Kim C-J, Webby RJ, Choi Y-K: Isolation and characterization of novel H3N1 swine influenza viruses from pigs with respiratory diseases in Korea. J Clin Microbiol 2006, 44:3923-3927.

55. Ma W, Gramer M, Rossow K, Yoon K-J: Isolation and genetic characterization of new reassortant $\mathrm{H} 3 \mathrm{~N} 1$ swine influenza virus from pigs in the Midwestern United States. J Virol 2006, 80:5092-5096.

56. Lekcharoensuk P, Nanakorn J, Wajjwalku W, Webby R, Chumsing W: First whole genome characterization of swine influenza virus subtype $\mathrm{H} 3 \mathrm{~N} 2$ in Thailand. Vet Microbiol 2010, 145:230-244. 
57. Gregory V, Lim W, Cameron K, Bennett M, Marozin S, Klimov A, Hall H, Cox N, Hay A, Lin YP: Infection of a child in Hong Kong by an influenza A H3N2 virus closely related to viruses circulating in European pigs. J Gen Virol 2001, 82:1397-1406.

58. Tu J, Zhou H, Jiang T, Li C, Zhang A, Guo X, Zou W, Chen H, Jin M: Isolation and molecular characterization of equine H3N8 influenza viruses from pigs in China. Arch Virol 2009, 154:887-890.

59. Karasin Al, Brown IH, Carman S, Olsen CW: Isolation and characterization of H4N6 avian influenza viruses from pigs with pneumonia in Canada. J Virol 2000, 74:9322-9327.

60. Shaw M, Cooper L, Xu X, Thompson W, Krauss S, Guan Y, Zhou N, Klimov A, Cox N, Webster R, et al: Molecular changes associated with the transmission of avian influenza a $\mathrm{H} 5 \mathrm{~N} 1$ and $\mathrm{H} 9 \mathrm{~N} 2$ viruses to humans. J Med Virol 2002, 66:107-114.

61. Li H, Yu K, Yang H, Xin X, Chen J, Zhao P, Bi Y, Chen H: Isolation and characterization of H5N1 and H9N2 influenza viruses from pigs in China. Chin J Prev Vet Med 2004, 26:1-6.

62. Chen H, Smith GJD, Zhang SY, Qin K, Wang J, Li KS, Webster RG, Peiris JSM, Guan Y: Avian flu H5N1 virus outbreak in migratory waterfowl. Nature 2005, 436:191-192

63. Chen H, Deng G, Li Z, Tian G, Li Y, Jiao P, Zhang L, Liu Z, Webster RG, Yu K: The evolution of H5N1 influenza viruses in ducks in southern China. Proc Natl Acad Sci USA 2004, 101:10452-10457.

64. Lee JH, Pascua PNQ, Song M-S, Baek YH, Kim C-J, Choi H-W, Sung M-H, Webby RJ, Webster RG, Poo H, Choi YK: Isolation and Genetic Characterization of H5N2 Influenza Viruses from Pigs in Korea. J Virol 2009, 83:4205-4215.

65. Obenauer JC, Denson J, Mehta PK, Su X, Mukatira S, Finkelstein DB, Xu X, Wang J, Ma J, Fan $Y$, et al: Large-scale sequence analysis of avian influenza isolates. Science 2006, 311:1576-1580.

66. Fouchier RAM, Schneeberger PM, Rozendaal FW, Broekman JM, Kemink SAG, Munster V, Kuiken T, Rimmelzwaan GF, Schutten M, van Doornum GJJ, et al: Avian influenza A virus (H7N7) associated with human conjunctivitis and a fatal case of acute respiratory distress syndrome. Proc Natl Acad Sci USA 2004, 101:1356-1361.

67. Butt KM, Smith GJD, Chen H, Zhang LJ, Leung YHC, Xu KM, Lim W, Webster RG, Yuen KY, Peiris JSM, Guan Y: Human infection with an avian H9N2 influenza A virus in Hong Kong in 2003. J Clin Microbiol 2005, 43:5760-5767.

68. Guo Y, Li J, Cheng X, Wang M, Zhou Y, Li C, Chai F, Liao H, Zhang Y, Guo J, et al: Discovery of men infected by avian influenza A (H9N2) virus. Chinese J Exp Clin Virol 1999, 13:105-108.

69. Peiris JSM, Guan Y, Markwell D, Ghose P, Webster RG, Shortridge KF: Cocirculation of avian H9N2 and contemporary "human" H3N2 influenza A viruses in pigs in southeastern China: potential for genetic reassortment? J Virol 2001, 75:9679-9686.

doi:10.1186/1743-422X-8-395

Cite this article as: Dong et al:: Detecting transmission and reassortment events for influenza $A$ viruses with genotype profile method. Virology Journal 2011 8:395.

\section{Submit your next manuscript to BioMed Central and take full advantage of:}

- Convenient online submission

- Thorough peer review

- No space constraints or color figure charges

- Immediate publication on acceptance

- Inclusion in PubMed, CAS, Scopus and Google Scholar

- Research which is freely available for redistribution

Submit your manuscript at www.biomedcentral.com/submit
Biomed Central 